\title{
EVALUATION OF FREE PLATFORMS FOR DELIVERY OF MASSIVE OPEN ONLINE COURSES (MOOCS)
}

\author{
Airton ZANCANARO \\ Federal Institute Catarinense \\ Sao Bento do Sul, Brazil \\ Carolina Schmitt NUNES \\ State University of Santa Catarina \\ Florianopolis, Brazil \\ Maria Jose Carvalho de Souza DOMINGUES \\ Management Department \\ Regional University of Blumenau \\ Blumenau, Brazil
}

\section{ABSTRACT}

For the hosting, management and delivery of Massive Open Online Courses (MOOC) it is necessary a technological infrastructure that supports it. Various educational institutions do not have or do not wish to invest in such a structure, possibly because MOOCs are not yet part of official programs of universities, but initiatives by a particular teacher or a research group. Focusing on this problem, this study seeks to identify platforms that make it possible to create, host and provide courses free of charges for the offeror; find in the respective literature, the basic requirements for MOOC platforms and to evaluate the platforms based on the raised requirements. In order to identify the platforms, information was sought in scientific articles and websites dealing with the comparison of platforms and listing the existing MOOC providers. For the definition of evaluation requirements, there was a search in the Web of Science and Scopus databases, looking for the term "Massive Open Online Courses". After applying some filters, 62 works that address platforms and technology were selected for analysis. As a result there is the identification of six platforms that allow the free supply of courses, the proposal for 14 requirements for reviewing them and a frame containing the evaluation of the identified platforms. This assessment is important since it brings knowledge as a basis for selecting a platform that is the most suitable one in terms of the chosen structure and method to store, manage and deliver courses in MOOC format.

Keywords: MOOC platforms, MOOC, requirements, free platforms.

\section{INTRODUCTION}

The widespread availability of access to computing devices and the Internet allows educational resources and social media to create opportunities for new business models focused on education (Ahn, Weng, \& Butler, 2013). The Massive Open Online Courses (MOOCs), have the characteristic of bringing disruptive innovation (Comeau \& Cheng, 2013) into the educational system, as it happens whenever teachers adopt new technologies and innovative practices (Iqbal, Zang, Zhu, Chen, \& Zhao, 2014). This transformation in education, as clarified by Sivamuni and Bhattacharya (2013), is not on Information Technology, but rather on the teaching and learning process. 
The MOOCs, by being available to anyone with internet access, are considered a way to allow access to teaching and to democratize learning throughout life (Meyer \& Zhu, 2013), since students do not need to attend physical institutions to have classes nor to pay any tuition (Chen, 2014), creating opportunities for knowledge socialization (Stuchlikova \& Kosa, 2013). In educational institutions, this new course model emerges at a time when institutions are committed to attracting new students (bypassing geographical barriers), reducing educational costs and reusing existing materials.

The MOOC is an open course at no cost to the learner (Chen, 2014). However, it does not mean this model offers no cost to those who produce them and make them available. Simultaneously delivering a course to thousands of user needs, besides a technical staff for its production and support (Claros et al., 2013), a robust and scalable technology infrastructure (Meinel, Totschnig, \& Willems, 2013). MOOCs can also be seen as a new business model. To this end, there are some issues to be discussed, being among them the financial viability and long-term sustainability.

Regarding technology, Clarke (2013) emphasizes the need for strategic investments in necessary infrastructure for the availability of MOOCs. However, not all educational institutions can afford or are willing to make such investments, as open education are not often part of official programs at universities (Claros et al., 2013) but initiatives by a certain teacher or a research group. This work intends to act in this scene of budgetary and structural constraints experienced by several universities, which prevents the expansion of an adequate infrastructure for the provision of MOOCs.

While building, deploying and maintaining learning environments dedicated to host MOOCs require a large amount of financial resources, the use of open platforms can help reduce these costs by providing subsidies for their storage and management (Claros et al., 2013). Thus, it is possible to build MOOCs focusing efforts and resources on the production of materials and not on the technological infrastructure needed to store, manage and deliver the course to the interested public.

The MOOC platforms are a central access point which has the function of managing MOOC courses (Jurado \& Redondo, 2014). These platforms are not different from the traditional Learning Management System (LMS), regarding the tools to control the participants and the distribution of course content. The main difference is in the ability to handle thousands of students simultaneously accessing the environment (Gillet, 2013), apart from copyright and cost policies, exclusivity and ownership of course participants' data (Johnson, Prandoni, Pinto, \& Vetterli, 2013).

Considering a technological approach and the context of educational institutions that do not have infrastructure to deposit MOOCs, we ask: how is it possible to identify and evaluate platforms that make it possible to store, manage and deliver courses for free?

Considering this research question, the article aims to: a) identify the platforms that make it possible to store, manage and deliver MOOCs for free; b) locate, based on literature, the basic requirements for MOOC platforms and; $c$ ) evaluate the platforms based on the identified requirements. For this purpose, it is initially presented a literature review on MOOCs and the MOOC platforms available for hosting and managing courses. In the sequence, this paper brings the works related to this research, the methodological procedures and, finally, the achieved results and closing remarks. 


\section{LITERATURE REVIEW}

The MOOCs, as the name suggests, are courses designed to meet a large number of students geographically dispersed (Stuchlikova \& Kosa, 2013). These courses integrate social networks, online resources and trained teachers in the study area (Clarke, 2013). Also, they take advantage of universities' expertise when it comes to distance education.

The term MOOC was coined by Dave Cormier and Bryan Alexander (Iqbal et al., 2014) to describe the course called "Connectivism and Connective Knowledge" in 2008 (Stuchlikova \& Kosa, 2013). However, the term raised widespread interest in 2011 when the course "Artificial Intelligence" was offered by Sebastian Thrum. In this course there were more than 160,000 participants from 190 countries, and 23,000 of them completed it (Iqbal et al., 2014).

The MOOCs can be classified into two main pedagogical trends: $x M O O C s$ and cMOOCs. The first follows a behaviorist pedagogy focused on the content or the teacher (Chen, 2014). The second one is focused on the connectivist approach and has a sophisticated and innovative way of learning: based on students' connection (Estévez-Ayres, Crespo-García, Fisteus, \& Kloos, 2013). The central idea of the connectivist approach is that knowledge can be transmitted through the network connections (Rogers, Chan, \& Isom, 2007), resulting in learning viewed through the learner's ability to establish and use networks (Leontyev \& Baranov, 2013; Rodriguez, 2013, 2014).

The concept of MOOC is presented as a model for open courses, which means that anyone can join it and have access to its material and activities, without paying anything for that. However, several institutions charge those who wish to obtain a certification. Moreover, it is participatory and distributed because it enables the exchange of ideas among participants and access to the used materials (videos, links, texts), creating a network of connected content (Vaidya \& Paranjape, 2014). It is not the purpose of MOOCs to replace formal education but to be an alternative to traditional training, expanding learning throughout life.

There are a number of terms that designate the location where MOOCs are stored, managed and made available. The most common ones are MOOC services and MOOC and LMS providers (Sivamuni \& Bhattacharya, 2013). This work will use the term MOOC platforms for understanding that they are entities - online education websites (Pernías Peco \& LujanMora, 2013) - that provide a storage system, allowing the management of the entire life cycle of a course and making MOOCs available to a group of participants.

Such platforms are intended to provide independent producers' courses or courses in collaboration with universities (Chen, 2014) and they connect teachers and learners, supporting the entire MOOC cycle. Therefore, Coursera and edX are regarded as the main platforms for MOOCs (Iqbal et al., 2014).

In turn, the LMS systems (such as Moodle, Blackboard and Sakay) are more complete systems than those used in some MOOC platforms, especially when it comes to targeted tools for the design of activities (Kay, Reimann, Diebold, \& Kummerfeld, 2013). However, they present scalability problems because they were not designed to support access by thousands of students at the same time (Pernías Peco \& Lujan-Mora, 2013). Even with this limitation the Moodle, for example, is being used by some MOOC platforms as an open source management system.

There are currently three ways to store, manage and deliver MOOCs: The first possibility is the offering institution having its own technological infrastructure. This demands high initial 
cost to implement, but enables access and complete control of all technology used. The second alternative is to adhere to proprietary platforms that require, in most cases, signing a contract, a partnership agreement and/or the payment of fees for maintenance. The third possibility is to opt for platforms that allow that the courses are available at no cost to the issuer (Pernías Peco \& Lujan-Mora, 2013). All of them have advantages and disadvantages that should be evaluated by the course syllabus production team.

\section{Related Works}

When it comes to works related to this research, there is the use of open services in which Claros et al. (2013) sought to integrate the freely available tools in an online educational system. In contrast, Gillet (2013) focuses on the development of personal learning environments in order to assist teachers and learners in the aggregation of the free resources available on the Web - as Twitter, YouTube and Facebook - to their MOOCs. Sivamuni and Bhattacharya (2013) highlight a nomenclature on MOOC in their work, in which they include platforms, and also bring an analysis of different existing MOOC providers.

Regarding the definition of requirements, there are three relevant researches: the one by Leontyev and Baranov (2013), which evaluated chemistry courses available on different platforms, based on key attributes for MOOCs listed by the authors; another by Pernías Peco and Lujan-Mora (2013), in which the authors describe the construction of a course using Google CourseBuilder and then evaluate the platform and; one by Meinel et al. (2013) that highlights the important requirements for a virtual MOOC environment. Following, the methodological procedures adopted in this research will be presented.

\section{METHODOLOGICAL PROCEDURES}

This work is characterized as a predominantly qualitative research and it is divided into three steps outlined below.

\section{Selection of MOOC Platforms Available for Use}

For the selection of MOOC platforms that allow storing, management and delivery of courses for free, the following procedures were taken:

$>$ Search for MOOC platforms: this search was performed in scientific papers, on websites that deal with the comparison of platforms, on sites that link existing MOOC providers and on Google search environment using the terms "Aggregate MOOC", "MOOC Platform" and "MOOC Provider". This step was completed in November 2015 and identified 53 operative MOOC platforms.

$>$ Selection of platforms that allow storing, management and delivery courses for free: in this phase the following criteria were applied: a) Removal of MOOC platforms whose interface is in Mandarin, Korean and Japanese; b) Removal of platforms that clearly do not offer the possibility of including courses for free; c) The application of the criteria I and II resulted in the elimination of 31 platforms, leaving 22 of them. Of those, only 06 had, on their websites, the information that courses could be freely added in their platform. For the other 16 ones, it was necessary to get in touch with the providers to ask about the possibility for the courses to be available on the platform at no cost to the issuer. After ten working days, given as a waiting period for the reception of responses, nine platform providers responded to questioning. Three reported that they offered the service for free. Thus, those platforms that did not respond to the contact and also those that do not allow courses to be freely disposed were withdrawn from the analysis set. 
$>$ Of the nine identified platforms, it was found that three did not offer to the user the possibility to create courses via interface. For those, access to a course as a teacher or administrator was requested in order to fully test and evaluate the functionality of the platform. In such case, the three platforms were removed from the final analysis because: they required filling a form for further feasibility analysis; they asked the course developer to take a prior course, offered by the platform provider, before releasing the course or they did not offer a position to specifically assess their platforms. Thus, six platforms remained for analysis.

\section{Identification in the Literature of Requirements for the Evaluation of Platforms}

Once the platforms to be evaluated were selected, the second stage of the research began: to identify basic requirements for the evaluation of platforms in the scientific literature. To this end, a survey was initially performed using the term "Massive Open Online Courses" in Scopus and Web of Science databases on July 13, 2015. The search was restricted to studies published up to December 31, 2014 in the languages English, Spanish and Portuguese. From the selected works, those who were out of context and that did not provide the full text to read for free were removed, thus forming a set of $\mathbf{2 9 4}$ publications for analysis.

From the reading of the title, keywords and abstract and, in case of doubt, the full text, the works were classified into macro themes. For this study, 62 publications dealing with the subject technology were selected and the requirements for the evaluation of platforms were extracted from them.

\section{Evaluation of MOOC Platforms Using the Requirements Determined in the Previous Step}

After identifying the platforms as described in Step 1 and confronting them with the requirements set out in Step 2, it was possible to assess the raised platforms, which offer free storage, management and delivery of courses in MOOC format, in order to check whether they satisfactorily meet those requirements. In order to facilitate the evaluation of the requirements, for each platform was created a fictitious course containing the following features: a) a forum; b) a text containing an image; c) a link to a video filed in http://vimeo.com site; d) the creation of a questionnaire type activity.

\section{RESULTS}

The outcomes of this research will be shown in three parts: the first one deals with presenting the MOOC platforms selected in this research that allow storing, managing and delivering MOOC courses at no cost to the issuer; the second one sets the minimum requirements identified in the literature for the evaluation of platforms; finally, the third one is dedicated to the evaluation of platforms using the requirements.

\section{MOOC Platforms}

After the application of the different criteria for selection, defined in the methodological procedures in Table 1, it is shown the selection of platforms that allow storing, managing and delivering courses for free, with a brief description of each one. 
Table 1. Selected platforms

\begin{tabular}{|c|c|}
\hline Platform & Description \\
\hline Open Learning & $\begin{array}{l}\text { The Open Learning (https://www.openlearning.com) started at the University } \\
\text { of New South Wales in Australia, as a startup. Currently it has more than } 1040 \\
\text { courses, in various areas of knowledge, in different languages and it has about } \\
125 \text { thousand users. It enables a person - or group of individuals - unlinked } \\
\text { from a university to create courses and make them available on the platform. } \\
\text { The platform establishes a } 10 \% \text { rate of value if the issuer chooses to offer paid } \\
\text { courses or monthly values for priority support. E-mail support is offered for free } \\
\text { (OpenLearning, 2016). }\end{array}$ \\
\hline CourseSites & $\begin{array}{l}\text { The platform CourseSites (https://www.coursesites.com) was made available } \\
\text { by Blackboard in February } 2011 \text { (Tekdal, Baz, \& Catlak, 2015) and it enables } \\
\text { people, connected or not to educational institutions, to create and offer courses } \\
\text { for free. Currently it has over } 12,000 \text { registered institutions in } 129 \text { countries. } \\
\text { The platform is free for teachers and students, without any fees for the } \\
\text { implementation of the courses. However, for institutional use a licensing } \\
\text { agreement is required. Support is offered for free to teachers and students, via } \\
\text { chat, phone or email (CourseSites, 2016). }\end{array}$ \\
\hline $\begin{array}{l}\text { P2PU (Peer } 2 \text { Peer } \\
\text { University) }\end{array}$ & $\begin{array}{l}\text { The platform Pear } 2 \text { Pear University (https://courses.p2pu.org) was founded in } \\
2009 \text { by Hewlett Foundation and Shuttleworth Foundation. Besides offering } \\
\text { MOOCs, it also provides an opportunity to anyone who is willing to teach and } \\
\text { learn, to do it online and for free (Yuan \& Powell, 2013). The technology used is } \\
\text { open to allow experimentation and continuous improvement. The business } \\
\text { model is based on users' donations (Tovar, Dimovska, Piedra, \& Chicaiza, 2013). }\end{array}$ \\
\hline Versal & $\begin{array}{l}\text { Versal (https://versal.com/) is a North American platform maintained by the } \\
\text { Versal Foundation, focused on interactivity and co-creation of courses } \\
\text { (Kesselman, 2014). It has two versions: one facing the educational context and } \\
\text { another for business. The platform is free for those who want to create public } \\
\text { courses. As for the private courses, to access students' progress assessments } \\
\text { and for centralized management of schools, an annual fee is required (Versal, } \\
2016 \text { ). }\end{array}$ \\
\hline Udemy & $\begin{array}{l}\text { The platform Udemy (https://www.udemy.com/) was launched in } 2010 \text { by Eren } \\
\text { Bali, Oktay Caglara and Gagan Biyani in the US with an investment of } 16 \text { million } \\
\text { dollars of venture capital (Wilson \& Gruzd, 2014; Yuan \& Powell, 2013). } \\
\text { Currently the platform has more than nine million students and 35,000 courses } \\
\text { in over } 80 \text { languages. For paid courses, Udemy charges } 50 \% \text { marketing fee for } \\
\text { management and for each student captured by the platform (Udemy, 2016). }\end{array}$ \\
\hline Eliademy & $\begin{array}{l}\text { The platform Eliademy (https://eliademy.com) was founded by Sotiris } \\
\text { Makrygiannis and Sergey Gerasimenko in } 2012 \text { in Finland. Its system is based } \\
\text { on LMS Moodle and it is available in over } 19 \text { languages, including Latin (Tanas, } \\
\text { 2015). The platform may be used by schools and universities to create and } \\
\text { deliver online courses, acting as a content repository and provider. In order to } \\
\text { use the Premium version, that is, to offer private courses, it is necessary to pay } \\
\text { a monthly rate for each student in the courses (Eliademy, 2016). }\end{array}$ \\
\hline
\end{tabular}

Please note that the platforms mentioned here do not require prior contract, agreement or partnership between the parties, that is, anyone who wishes to offer a course, can simply do it by creating a profile and accessing the area of creating courses.

In order to compare the platforms and identify the one that best suits the MOOC course issuer's needs, it is necessary to identify requirements expressing the basic conditions that a platform should provide. Overlooking this, it was sought to identify such requirements in the scientific literature, and they will be presented in the next topic. 
Requirements for Platform Evaluation

Accreditation: Accreditation refers to the student's possibility to receive a certificate after the course, once they have carried out the activities planned with a predetermined quality level. Nkuyubwatsi (2013) and Nkuyubwatsi (2014) point out that accreditation is as important as their own open course, because students can expand their participation by improving knowledge about a certain subject and thus prove participation. In this requirement, it shall be assessed whether the platform offers the possibility for the issuer to allow the student to obtain a certification at the end of the course, whether paying or not for it.

Accessibility: Accessibility means that anyone is able to perceive, understand, navigate and interact, as they can also help others through MOOC platforms (Caballe, Britch, Barolli, \& Xhafa, 2014). Therefore, a platform should offer any person with an Internet access device, whether or not the bearer of special needs, the possibility to build and accomplish a course (Vaidya \& Paranjape, 2014). So, this requirement should assess if the platform is accessible and visible on computers and mobile devices. In addition, it is necessary to verify whether the platform interface offers the possibility to select the language, so that the users can choose the one they are most comfortable with.

Usability: For Fini (2009) usability is the ability humans have in using a system in a facilitated way, with effectiveness and efficiency. The platform should offer intuitive and useful tools for editing and structuring content, encouraging its use, keeping a familiar environment for users and reducing the cognitive load of learning that involves its use (Meinel et al., 2013). To assess the MOOC platforms, it is suggested to use the System Usability Scale (SUS), a questionnaire developed by Brooke (1996) in order to verify the level of usability of a system. For the overall score, the criteria set by the NHS are applied and the final value can range from 0 to 100 . The higher the final value, the higher the usability rate.

Information security: A critical aspect in MOOC platforms is the security of information, i.e., only administrators and teachers are able to create, modify or delete course content. On the other hand, students interact in basic form - participating in forums, answering questionnaires, writing collaborative texts - and only in specific situations they are allowed to create resources (Montes et al., 2013). The authentication of a system is another important point to ensure that personal information and course materials are not deleted or improperly modified (Miguel, Caballé, \& Prieto, 2013). For such reason, this requirement evaluates whether there is a need of a password to access to the course in order to verify the user's identity and whether there are rules to differentiate teachers' access from students' access.

Platform policies related to costs and copyright: According to Johnson et al. (2013) and Chen (2014) platforms typically offer the same tools, but what changes are policies for author's rights on materials produced and costs so that "something more" is available. In this requirement, it should be assessed whether the platform has clear information on the policies of costs and copyright of the deposited material.

Interaction/collaboration tools: Interaction and collaboration are key elements to make the environment dynamic in order to increase student's permanence and achievement in a MOOC (Meinel et al., 2013). An interactive and collaborative environment enables participants to work together in a space where communication is fluent (Claros et al., 2013). For that 
reason, the platform needs to offer communication tools that enable the collective participation of a large number of students, such as forums or the Web 2.0 (Ahn et al., 2013; Claros et al., 2013; Montes et al., 2013). Therefore, in this requirement it should be assessed whether the platform provides a forum tool for student-student and student-teacher communication.

Report submission tool: Sending mass email allows reports to be issued to participants enrolled in the course in an easier way (Pernías Peco \& Lujan-Mora, 2013). In this requirement, it should be assessed if the platform offers the possibility to send e-mails to students enrolled in the course.

Content management tool: The platform should allow access to course materials in an easier way in order to attract participants for a positive online experience (Meinel et al., 2013). To do so, it should support the distribution of multimedia content and provide resources for administration (Montes et al., 2013). In this requirement it should be assessed whether the platform offers the ability to incorporate video, text, audio and images, besides allowing the connection of external tools, such as YouTube, Vimeo, Quizlet, Google Docs, Dropbox, Wikipedia, Slideshare and Prezi, to the MOOC that will be available on the platform.

Activity tool: According to Meinel et al. (2013), a platform should offer support to the learning process, allowing learners to test new skills and evaluate their progress in the course by means of activity resources. Therefore, in this requirement it should be assessed whether the platform offers a tool for providing online exercises.

Course schedule management: For Meinel et al. (2013) a platform should enable the management of course schedule. Therefore, in this requirement it should be assessed whether the platform allows the settings of course start and completion dates, as well as of deadlines for the submission of activities.

Tools for managing participants: A MOOC platform should offer features that enable teachers and administrators to manage course students, as said by Montes et al. (2013). Moreover, it should provide reports of students' activity and access. Assessing, monitoring and analyzing MOOC participants' activities is extremely important, to help improve course and content organization (Claros et al., 2013). In this requirement, it should be assessed whether the platform provides access statistics tools and reports of students' activities in the course.

Gamification tool: The Karma points (that the participant gets through positive feedback from other participants) and Badges (which are issued automatically by the platform when a certain goal is achieved) are motivational systems that encourage learning and collaboration throughout the course (Al-Atabi \& Deboer, 2014; Anderson, Huttenlocher, Kleinberg, \& Leskovec, 2014). The greater the number of Karma and Badges, the higher are the chances of getting prizes or even credibility within the community (Martín-Monje, Bárcena, \& Read, 2014). In this requirement it is assessed whether the platform offers Karma or Badges scoring mechanisms.

Connection with social networks: Social networking platforms are characterized for allowing high interaction among participants, enabling understanding, mutual aid and participation in learning activities (Claros et al., 2013). According to Meinel et al. (2013), the platform should 
facilitate a network among participants and should not block the user in their own limits, but allow them to connect their learning experience with their social networks. Therefore, in this requirement it should be assessed whether the platform offers the possibility to connect with social networks, as Facebook and Twitter.

Course visibility/dissemination (Marketing strategy): According to Johnson et al. (2013) and Pernías Peco and Lujan-Mora (2013), MOOC platforms contribute to increase the visibility of the institutions and of the courses kept by them. For such reason, in this requirement it is assessed whether the platform offers a list of provided courses, so that the interested parties can quickly choose and attend the ones desired. Table 2 summarizes the requirements for the assessment of MOOC platforms.

Table 2. Summary of requirements

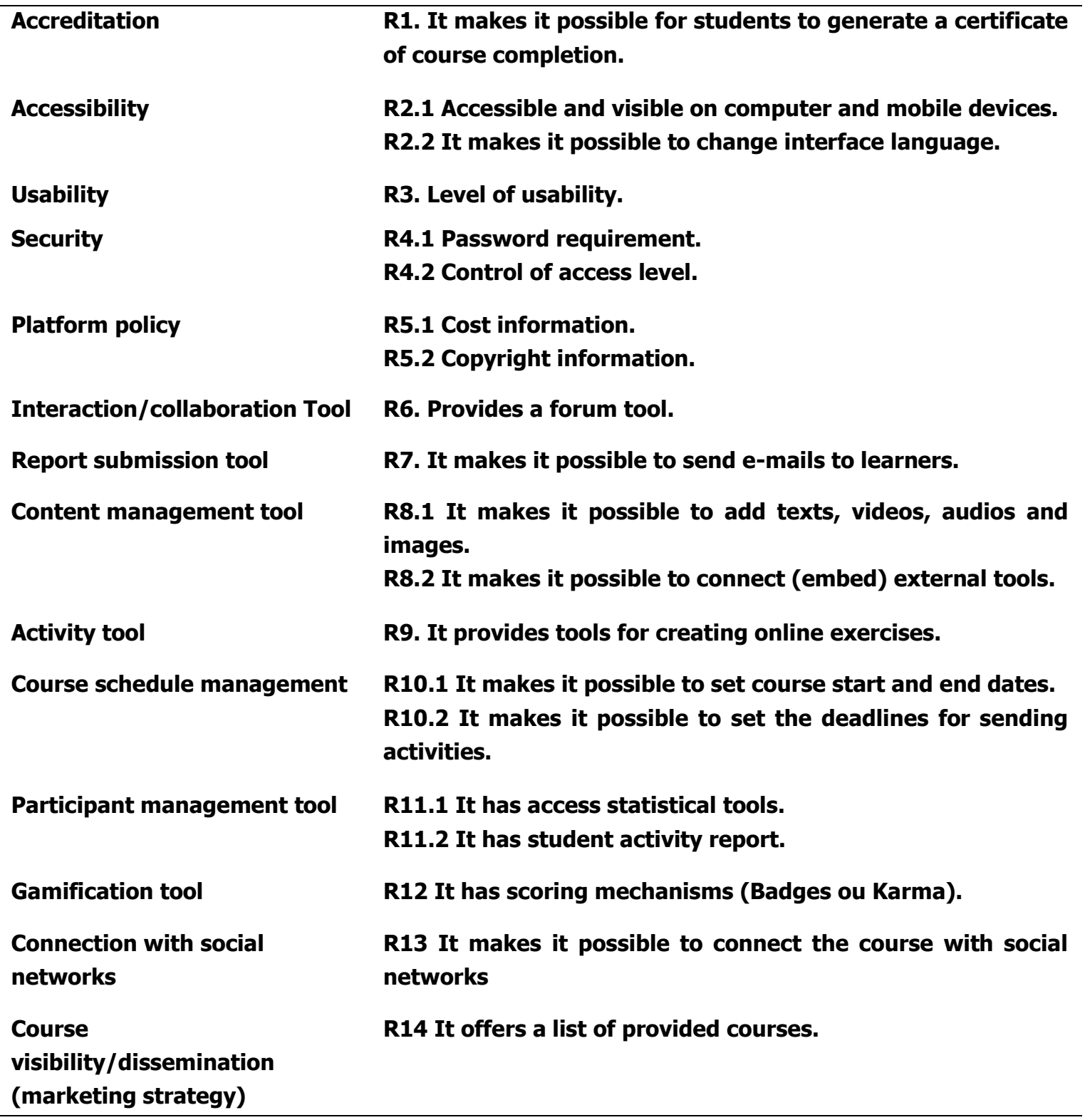




\section{Platform Evaluation}

The platforms were evaluated in January 2016, according to the procedures already described in the previous section. It should be noted that the course made available in the platforms was created only for testing and it was not available to the public. Table 3 presents the evaluation of each platform according to the established requirements.

Table 3. MOOC Platform evaluation

\begin{tabular}{|c|c|c|c|c|c|c|}
\hline Requirements & $\begin{array}{l}\text { Open } \\
\text { Learning }\end{array}$ & CourseSites & 2PU & Versal & Udemy & Eliademy \\
\hline R1 & $\checkmark$ & $x$ & $x$ & $x$ & $x$ & $\checkmark$ \\
\hline R2.1 & $\checkmark$ & $\checkmark$ & $\checkmark$ & $\checkmark$ & $\checkmark$ & $\checkmark$ \\
\hline R2.2 & $x$ & $x$ & $\checkmark$ & $x$ & $\checkmark$ & $\checkmark$ \\
\hline R3 & 82.5 & 75.6 & 65.6 & 83.8 & 67.5 & 87.5 \\
\hline R4.1 & $\checkmark$ & $\checkmark$ & $\checkmark$ & $\checkmark$ & $\checkmark$ & $\checkmark$ \\
\hline R4.2 & $\checkmark$ & $\checkmark$ & $\checkmark$ & $\checkmark$ & $\checkmark$ & $\checkmark$ \\
\hline R5.1 & $\checkmark$ & $\checkmark$ & $\checkmark$ & $\checkmark$ & $\checkmark$ & $\checkmark$ \\
\hline R5.2 & $\checkmark$ & $\checkmark$ & $\checkmark$ & $\checkmark$ & $\checkmark$ & $\checkmark$ \\
\hline R6 & $\checkmark$ & $\checkmark$ & $\checkmark$ & $\checkmark$ & $\checkmark$ & $\checkmark$ \\
\hline R7 & $\checkmark$ & $\checkmark$ & $x$ & $x$ & $x$ & $\checkmark$ \\
\hline R8.1 & $\checkmark$ & $\checkmark$ & $\checkmark$ & $\checkmark$ & $\checkmark$ & $\checkmark$ \\
\hline R8.2 & $\checkmark$ & $\checkmark$ & $x$ & $\checkmark$ & $x$ & $\checkmark$ \\
\hline R9 & $\checkmark$ & $\checkmark$ & $x$ & $\checkmark$ & $\checkmark$ & $\checkmark$ \\
\hline R10.1 & $\checkmark$ & $\checkmark$ & $\checkmark$ & $x$ & $x$ & $\checkmark$ \\
\hline R10.2 & $\checkmark$ & $\checkmark$ & $x$ & $x$ & $x$ & $\checkmark$ \\
\hline R11.1 & $\checkmark$ & $\checkmark$ & $x$ & $x$ & $\checkmark$ & $\checkmark$ \\
\hline R11.2 & $\checkmark$ & $\checkmark$ & $x$ & $x$ & $\checkmark$ & $\checkmark$ \\
\hline R12 & $\checkmark$ & $x$ & $\checkmark$ & $x$ & $x$ & $x$ \\
\hline R13 & $\checkmark$ & $x$ & $\checkmark$ & $\checkmark$ & $x$ & $\checkmark$ \\
\hline R14 & $\checkmark$ & $\checkmark$ & $\checkmark$ & $\checkmark$ & $\checkmark$ & $\checkmark$ \\
\hline
\end{tabular}

Legend: $\checkmark$ It meets the requirement $\quad x$ It doesn't meet the requirement

It is important to emphasize that only the Udemy course needed to go through quality assessment by the team responsible for the platform before being made available to the public. This platform is targeted to people who want to easily build their courses and offer them to the public free of charge or through payment. For convenience, the platform offers a variety of information that assist in the creation and delivery of materials by teachers. 
It is noted that the platforms Open Learning, CourseSite, Udemy and Eliademy were built for the purpose of controlling the entire process of MOOC production and providing. On the other hand, P2PU and Versal, in their free version, are characterized by a fast and easy availability of materials created by the teachers, but they are not so careful to manage participants or dates.

As for advertising, Udemy and Open Learning platforms regularly send e-mails to registered users, promoting their courses. There are also applications (apps) that may be freely installed, making it easier the interaction with users that have mobile devices.

CourseSites, due to its LMS Blackboard origin, offers a wide variety of tools that other platforms do not have which may require the users a higher cognitive load for learning in the platform. On the other hand, Eliademy and Open Learning are platforms that have fewer resources for making content and tasks available, which may require the users a lower cognitive load for learning in the platform. It is important to emphasize that CourseSites is the only platform that offers the possibility to incorporate materials in SCORM format.

Therefore, evidences indicate that Open Learning and Eliademy are the platforms meeting the greatest number of requirements, the first one not meeting only the R12 requirement concerning gamification tools. It is also worth noting that the Eliademy platform scored highest in the usability requirement. However, it is worth noting that the issuer of courses in MOOC format needs to select a platform that is more appropriate to the structure and chosen method, taking into account the most important requirements for that particular context.

\section{CONCLUSION AND FUTURE STUDIES}

This study aimed to identify platforms that enable hosting courses for free, to set requirements for measuring platforms and to evaluate them. From the data obtained in this work, developers can assess the advantages of running their courses on their own platforms or on free MOOC platforms.

A limitation of this article is regarding the usability evaluation of MOOC platforms. The usability of a platform is difficult to measure and may vary according to the user's understanding, experience and ability in dealing with technology. Therefore, in this work, evaluating the usability was restricted to researchers. Each one made their evaluation separately and the overall SUS score had its origin in the average score of the evaluations. For future work, it is recommended to have a greater number of users evaluate this requirement, with their different perceptions regarding the use of technology and, thus, it may bring a more reliable assessment of the usability of platforms.

Another point to be highlighted in the development and availability of a MOOC is the platform scalability. Scalability is the ability that the system has to extend its capacity as the number of users grows. Without this capacity, systems cannot support large number of users accessing the course at the same time, thus requiring expansion (Pernías Peco \& Lujan-Mora, 2013). Even though it is considered an important requirement, scalability evaluation is not possible due to the need of access to servers in which platforms are hosted in order to perform load tests.

All platforms selected in this work require that the issuer fits the rules of use established by the portal for building materials. There is no freedom to go beyond what is offered. In 
addition, there is always the question of how long the services will be offered for free. So it is important to make a careful analysis of the platforms in order to select the one that best suits the MOOC producer's needs.

Finally, it is believed that this work can help those who do not have adequate technological infrastructure to store, manage and provide a MOOC and wish to contribute in order to democratize knowledge and promote global citizenship. The paradigm of online learning is still new, but it has already been influencing the teaching and learning ways. So, having a platform that can adequately meet both teachers' and students' expectations is the first step to make knowledge a public good.

Future studies will assess free tools that allow the installation of MOOC platforms in institutions' own servers, allowing their full management, as it occurs with TIMTEC platform (Ribeiro, Catapan, Roncarelli, Vanzin, \& Silveira, 2015).

\section{BIODATA and CONTACT ADDRESSES of AUTHORS}

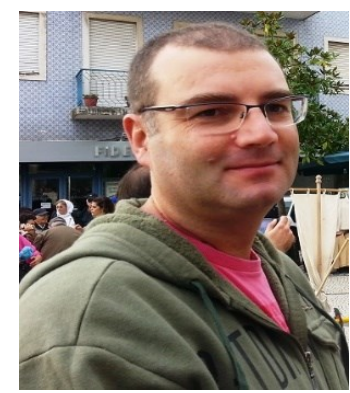

Airton ZANCANARO received an undergraduate degree Computer Science for the Regional University of Blumenau (1999). He completed his Masters in Knowledge Engineering and Managment at the Federal University of Santa Catarina (2011) and Doctorate in Knowledge Engineering and Managment at the Federal University of Santa Catarina (2015). He is currently a professor at the Federal Institute Catarinense and associated reseacher with the UNESCO Chair in Open Education (Unicamp). Research interests include Distance Education, Open Education and Open Educational Resources.

\section{Airton ZANCANARO \\ Instituto Federal Catarinense \\ Paulo Chapiewski, 931, CEP:89283-064 Sao Bento do Sul - Brasil \\ Phone: +55 47 3626-7332 \\ E-mail: airton.zancanaro@sbs.ifc.edu.br}

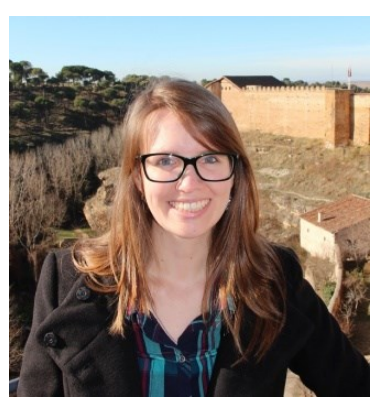

Carolina Schmitt NUNES received a bachelor's degree in Management from the Universidade Federal de Santa Catarina (2011). She completed her Masters (2013) and doctorade (2017) in Knowledge Engineering and Managment at the same university. She is currently associated reseacher with the UNESCO Chair in Distance Education (UNED - SPAIN). Research interests include Distance Education, Management in distance education and social midias. She has a international book chapter and other national and international articles in indexed journals.

Carolina Schmitt NUNES

Universidade Federal de Santa Catarina

Campus Reitor Joao David Ferreira Lima, s/n

Trindade, Florianopolis-SC, 88040-900 Florianopolis, Brazil

Phone: +55 4899299687

E-mail: nunes.carolinas@gmail.com 


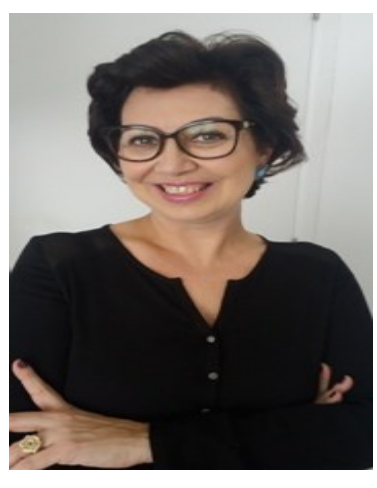

Maria Jose Carvalho de Souza DOMINGUES holds a degree in Management Sciences from the Universidade Federal de Santa Catarina (1986), a Master's degree in Management from the Universidade Federal de Santa Catarina (1991) and Doctoral in Production Engineering from the Federal University of Santa Catarina (2003). Professor at the Universidade Regional de Blumenau / FURB, in the Management Department. Experience in university management and has served as Director of the Center for Business Science, Pro-Reitora of Graduation and coordinator of the Graduate Program in Management of the Universidade Regional de Blumenau / FURB. Research interests include University Management and Technologies in Teaching

Maria Jose Carvalho de Souza DOMINGUES

Universidade Regional de Blumenau

Antonio da Veiga, 140, CEP:892030-903 Blumenau-Brazil

Phone: +55 47 3321-0565

E-mail: mariadomingues@furb.br

\section{REFERENCES}

Ahn, J., Weng, C., \& Butler, B. S. (2013). The dynamics of open, Peer-to-Peer learning: What factors influence participation in the P2P University? Paper presented at the 46th Annual Hawaii International Conference on System Sciences, HICSS 2013, Wailea, Maui, HI.

Al-Atabi, M., \& Deboer, J. (2014). Teaching entrepreneurship using Massive Open Online Course (MOOC). Technovation, 34(4), 261-264.

doi: 10.1016/j.technovation.2014.01.006

Anderson, A., Huttenlocher, D., Kleinberg, J., \& Leskovec, J. (2014). Engaging with massive online courses, Paper presented at the 23rd International Conference on World Wide Web, WWW 2014.

Brooke, J. (1996). SUS: A quick and dirty usability scale. In P. W. Jordan, B. Thomas, B. A. Wenermeester \& I. L. McClealland (Eds.), Usability evaluation in industry (pp. 189194). Londres: Taylor \& Francis.

Caballe, S., Britch, D., Barolli, L., \& Xhafa, F. (2014). A Methodological Approach to Provide Effective Web-based Training by using Collaborative Learning and Social Networks. 2014 Eighth International Conference on Complex, Intelligent and Software Intensive Systems (Cisis), 64-71. doi: 10.1109/cisis.2014.10

Chen, Y. (2014). Investigating MOOCs Through Blog Mining. International Review of Research in Open and Distance Learning, 15(2), 85-106.

Clarke, T. (2013). The advance of the MOOCs (massive open online courses): The impending globalisation of business education? Education and Training, 55(4), 403-413. doi: 10.1108/00400911311326036

Claros, I., Cobos, R., Guerra, E., De Lara, J., Pescador, A., \& Sanchez-Cuadrado, J. (2013). Integrating open services for building educational environments. Paper presented at the 2013 IEEE Global Engineering Education Conference, EDUCON 2013, Berlin. 
Comeau, J. D., \& Cheng, T. L. (2013). Digital "tsunami" in higher education: Democratisation Movement towards Open and Free Education. Turkish Online Journal of Distance Education, 14(3), 198-224.

CourseSites. (2016). CourseSites by Blackboasd is a free learning management system for K12 and Higher Ed Instructors enabling blended \& elearning. Retrieved 19 Jan. 2016, 2016, from https: // www.coursesites.com/

Eliademy. (2016). Eliademy | Create your own online course. Retrieved 19 Jan. 2016, 2016, from https://eliademy.com/

Estevez-Ayres, I., Crespo-García, R. M., Fisteus, J. A., \& Kloos, C. D. (2013). An algorithm for peer review matching in Massive courses for minimising students' frustration.

Journal of Universal Computer Science, 19(15), 2173-2197.

Fini, A. (2009). The Technological Dimension of a Massive Open Online Course: The Case of the CCK08 Course Tools. International Review of Research in Open and Distance Learning, 10(5).

Gillet, D. (2013). Personal learning environments as enablers for connectivist MoOCs. Paper presented at the 2013 12th International Conference on Information Technology Based Higher Education and Training, ITHET 2013, Antalya.

Iqbal, S., Zang, X., Zhu, Y., Chen, Y. Y., \& Zhao, J. (2014). On the impact of MoOCs on engineering education. Paper presented at the 2014 IEEE International Conference on MOOCs, Innovation and Technology in Education, IEEE MITE 2014.

Johnson, D. H., Prandoni, P., Pinto, P. C., \& Vetterli, M. (2013). Teaching signal processing online: A report from the trenches. Paper presented at the 2013 38th IEEE International Conference on Acoustics, Speech, and Signal Processing, ICASSP 2013, Vancouver, BC.

Jurado, F., \& Redondo, M. A. (2014). Learning tools interoperability for enhancing a distributed personal learning environment with support for programming assignments. Paper presented at the 16th International Symposium on Computers in Education, SIIE 2014.

Kay, J., Reimann, P., Diebold, E., \& Kummerfeld, B. (2013). MOOCs: So many learners, so much potential. IEEE Intelligent Systems, 28(3), 70-77. doi: 10.1109/MIS.2013.66

Kesselman, M. (2014). On the horizon: The 2014 Consumer Electronics Show in Las Vegas, Part II. Library Hi Tech News, 31(4), 1-6.

Leontyev, A., \& Baranov, D. (2013). Massive open online courses in chemistry: A comparative overview of platforms and features. Journal of Chemical Education, 90(11), 15331539. doi: 10.1021/ed400283x

Martin-Monje, E., Barcena, E., \& Read, T. (2014). La interaccion entre companeros y el feedback linguistico en los COMA de lenguas extranjeras. Profesorado, 18(1), 167183. 
Meinel, C., Totschnig, M., \& Willems, C. (2013). OpenHPI: Evolution of a MOOC platform from LMS to SOA. Paper presented at the 5th International Conference on Computer Supported Education, CSEDU 2013, Aachen.

Meyer, J. P., \& Zhu, S. (2013). Fair and equitable measurement of student learning in MOOCs: An introduction to item response theory, scale linking, and score equating. Research and Practice in Assessment, 8(1), 26-39.

Miguel, J., Caballe, S., \& Prieto, J. (2013). Providing information security to MOOC: Towards effective student authentication. Paper presented at the 5th IEEE International Conference on Intelligent Networking and Collaborative Systems, INCoS 2013, Xi'an.

Montes, R., Gea, M., Bravo-Lupianez, D., Molina, S., Bergaz, R., \& Ramos, A. (2013). Turning out a social community into an e-Learning platform for MOOC: The case of AbiertaUGR. Paper presented at the 1st International Conference on Technological Ecosystem for Enhancing Multiculturality, TEEM 2013, Salamanca.

Nkuyubwatsi, B. (2013). Evaluation of massive open online courses (MOOCs) from the learner's perspective. Paper presented at the 12th European Conference on eLearning, ECEL 2013, Sophia Antipolis.

Nkuyubwatsi, B. (2014). A cross-modal analysis of learning experience from a learner's perspective. Electronic Journal of e-Learning, 12(2), 195-205.

OpenLearning. (2016). OpenLearning: Teach and learnin online for free. Retrieved 19 Jan. 2016, 2016, from https: //www.openlearning.com/

Pernías Peco, P., \& Lujan-Mora, S. (2013, 2013). Architecture of a MOOC based on CourseBuilder. Paper presented at the 2013 12th International Conference on Information Technology Based Higher Education and Training (Ithet 2013).

Ribeiro, L. O. M., Catapan, A. H., Roncarelli, D., Vanzin, T., \& Silveira, R. A. (2015). MO0Cs como espaço de experimentação pedagógica: um novo contexto. In R. I. Busarello, P. Bieging \& V. R. Ulbricht (Eds.), Sobre educação e tecnologia: conceitos e aprendizagem (pp. 84-113). São Paulo: Pimenta Cultural.

Rodriguez, C. O. (2013). Two distinct course formats in the delivery of connectivist moocs. Turkish Online Journal of Distance Education, 14(2), 66-80.

Rodriguez, C. O. (2014). Mobimooc 2012: A new tree structure for the delivery of connectivist moocs. Turkish Online Journal of Distance Education, 15(1), 41-49.

Rogers, P. C., Chan, P., \& Isom, B. (2007). WEB 2.0 LEARNING PLATFORM: Harnessing Collective Intelligence. Turkish Online Journal of Distance Education-TOJDE, 8(3), 16-33.

Sivamuni, K., \& Bhattacharya, S. (2013). Assembling pieces of the MoOCs jigsaw puzzle. Paper presented at the 2013 IEEE International Conference in MOOC, Innovation and Technology in Education, MITE 2013, Jaipur.

Stuchlikova, L., \& Kosa, A. (2013). Massive open online courses - Challenges and solutions in engineering education. Paper presented at the 11th IEEE International Conference on Emerging eLearning Technologies and Applications, ICETA 2013, Stara Lesna. 
Tanas, M. (2015). Distance Education as an Object of Study and Reflection of Pedagogy in Poland. INTL JOURNAL OF ELECTRONICS AND TELECOMMUNICATIONS, 61(3), 237243.

Tekdal, M., Baz, F. C., \& Catlak, S. (2015). Current MOOC Platforms at Online Education. International Journal of Scientific and Technological Research, 1(2), 144-149.

Tovar, E., Dimovska, A., Piedra, N., \& Chicaiza, J. (2013). OCW-S: Enablers for building sustainable open education evolving OCW and MOOC. Paper presented at the 2013 IEEE Global Engineering Education Conference, EDUCON 2013, Berlin.

Udemy. (2016). Online Courses: 30,000+ On-demand Classes from Udemy. Retrieved 19 Jan. 2016, 2016, from https: //www.udemy.com/

Vaidya, S., \& Paranjape, A. (2014). MOOCs - Changing the way of education. Paper presented at the 2014 IEEE International Conference on MOOCs, Innovation and Technology in Education, IEEE MITE 2014.

Versal. (2016). Versal Business. Retrieved 19 Jan. 2016, from https://versal.com/

Wilson, L., \& Gruzd, A. (2014). MOOCs - international information and education phenomenon? Bulletin of the American Society for Information Science and Technology, 40(5), 35-40.

Yuan, L., \& Powell, S. (2013). MOOCs and Open Education: Implications for Higher Education (pp. 1-21): JISC CETIS. 